\title{
Australia eyes role in Gemini telescopes
}

[SYDNEY] Australia may, after all, be involved in the Gemini project to build twin telescopes in Hawaii and Chile, even though its chance of being a replacement for Chile ended when the Chilean government finally agreed to pay its fee just before the 1 September deadline set by the other Gemini countries.

At a meeting of the Anglo-Australian Observatory (AAO) board in Durham, England, last week, Australian representatives gained backing for their efforts from British members. Ian Corbett, director of science for the UK Particle Physics and Astronomy Research Council, and a member of both the $\mathrm{AAO}$ and Gemini boards, says he is "very hopeful that a solution can be found".

"We all recognize the benefits to Gemini if Australia were to join and contribute its expertise and additional funds," says Corbett. "We are therefore now working together to see if we can establish a basis on which Australia could be invited to join the collaboration."

Roger Bell, the AAO secretary, said after his return to Sydney this week that negotiations had begun on how Australia might join

\section{New research chief faces multiple challenges}

[SYDNEY] Vicki Sara, newly appointed as chair of the Australian Research Council (ARC) and the first woman in the post, says her first challenge is to ensure Australia's international competitiveness in research at a time of "extreme pressure on funding".

The council provides competitive, peer-reviewed grants for research in universities. Appointed for three years full-time, Sara succeeds Max Brennan, a physicist, who retired in August.

Brennan's departure had been signalled 12 months earlier, and the long delay by the Education Minister, Amanda Vanstone, in announcing a successor was publicly attacked by the country's four learned academies and the Australian vice-chancellors' committee, which were concerned that it presaged major changes to the ARC.

Sara's appointment has now been widely welcomed by these bodies. But the delay will cause a four-month hiatus, as she cannot leave her current job as dean of science at the Queensland University of Technology (QUT) until the beginning of next year.

Sara, who is 51 , gained a high reputation for her research in the endocrinology of fetal brain development during her 17 years at the Karolinska

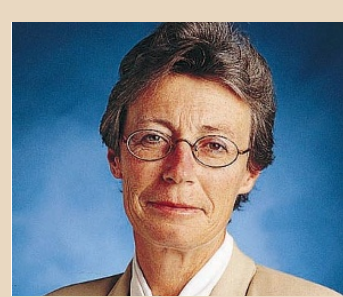

Sara: will encounter political tensions in a climate of cuts.

Institute in Stockholm, Sweden. After returning to Australia in 1993, she became the first director of the Cooperative Research Centre for Diagnostic Technologies, based at QUT.

On moving to Canberra, she will enter a tense political atmosphere characterized by continuing conflict between Vanstone and university researchers over the effects of cuts. Anxiety about the government's responses to recent reviews was heightened by Vanstone's statement, when announcing Sara's appointment, that the ARCwill soon be making "critical funding and programme decisions".

These decisions may have to be made before Sara can develop the ARC's first strategic plan, which she says will take six months.

Next May, the Coalition government delivers its third and last annual budget before the next federal election. The 1997 budget foreshadowed substantial cuts to research funding ARC 's budget will drop from
A $\$ 429$ million (US\$309 million) in 1997-98 to $\mathrm{A} \$ 381$ million in 2000-01 (see Nature 387, 222 \& 328; 1997).

Sara acknowledges that this situation poses a major challenge. "We must never give up the aim of improving our funding," she says, expressing particular concern at the effect on careers and international competitiveness of the fact that the ARC must "provide for an infrastructure on 27 cents in every dollar of research funding, whereas our aim should be 40 cents".

She believes the success rate in grant applications (21 per cent) is "too low", citing a "minimum rate of around 30 per cent in Europe".

Encouraging more cooperation between institutions and more sharing of major international facilities, such as Australian astronomers' attempt to join the Gemini telescopes project (see above), which she strongly supports, are Sara's first suggestions for alleviating the effects of cuts.

She is the first chair of the ARC to come to the post declaring a need "to boost the profile of research in the public and politics" through the ARC. She is an active promoter of the public understanding of science, having been involved in the 'QUT Science Train', an educational show for young people that is at present touring Queensland. as an additional partner. "Australia has come up with the money," he says, adding that while AAO itself cannot be a negotiating or funding party, a meeting between Gemini and Australian representatives could be arranged "soon".

Australia had an earlier opportunity for sharing in a large international telescope when invited by the European Southern Observatory (ESO) in 1994 to become its first non-European member in the Very Large Telescope (VLT), a set of four linked 8-metre instruments under construction in Chile.

The bid was foiled last year, however, when, shortly after the federal election, the new science minister, Peter McGauran, refused to commit the necessary funds of A \$25 million (US\$18.5 million) over six years while the conservative Coalition government was focusing on cutting expenditure (see Nature 381, 100; 1996).

Last May a new opportunity emerged when the Gemini consortium building the two 8-metre telescopes for US\$184 million approached Australia as a potential replacement for Chile. The Chilean government had blocked its cash share of Gemini along with separate contributions due for ESO and the US telescopes in the Andes.

The Gemini consortium — which includes the United States (50 per cent), the United Kingdom (25 per cent), Canada (15 per cent) and Brazil and Argentina (2.5 per cent each) — set a deadline of 1 September for Chile to pay its 5 per cent. The fee for Australia to join Gemini in place of Chile A $\$ 12$ million over four years, with $\mathrm{A} \$ 4.7$ million paid up-front — was less than its ESO membership fee.

While McGauran appeared to be supportive this time, despite a climate of continuing cuts in public expenditure, funds in his portfolio were consumed by research agencies and centres. Astronomers shifted their lobbying to the education minister, Amanda Vanstone, then found a champion in Max Brennan, a plasma physicist who then chaired the Australian Research Council (ARC).

Australia negotiated through a national consortium led by Jeremy Mould, director of the Mt Stromlo and Siding Spring Observatories of the Australian National University; the university runs three telescopes in New South Wales on the same site as the 3.9-metre Anglo-Australian Telescope operated by AAO.

While government officials expressed confidence, just before the Chilean deadline, that there would be an imminent "positive announcement" on funding, a letter of commitment had apparently already been sent from the ARC to the Gemini board in early August. Vicki Sara, newly appointed successor to Brennan (see panel), confirms the ARC's continuing support.

PeterPockley 